\title{
EL ARCO Y EL CETRO: PROBLEMAS DE LA PALABRA Y EL PODER EN LOS POEMAS HOMÉRICOS
}

\author{
GRACIELA ZECCHIN DE FASANO \\ Centro de Estudios de Lenguas Clásicas \\ Universidad Nacional de La Plata (Argentina)
}

\begin{abstract}
RESUMO: O presente artigo analisa o valor semântico contido na fórmula épica epea pteroenta e seus alomorfos como expressão dos antagonismos próprios do relato épico. Analisa, ainda, o modo pelo qual os ditos antagonismos - entre heróis, entre modalidades narrativas, entre diversos modos de desenho da trama e entre concepções de poder - se encontram cifrados em dois objetos de uso recorrente e de valor simbólico: o arco e o cetro.
\end{abstract}

PALAVRAS-CHAVE: Homero; Ilíada; Odisséia; palabra; poder.

Entre las múltiples variables interpretativas aceptadas para los poemas homéricos, podríamos incluir una lectura de Ilíada como testimonio de la corruptela arcaica de un basileus contra otro basileus subordinado en autoridad por la circunstancia de una guerra en coalición. Podríamos hacer extensiva ese tipo de lectura a Odisea y observarla como una excelsa competencia de justicia contra predadores des-ubicados. El resultado ineludible es el hecho de que los poemas homéricos se rebelan ante una interpretación unívoca y proponen ante toda disquisición la vasta problemática del epos, es decir, la vasta problemática de la palabra narrada, la inconmensurable potencia de las palabras, que puestas en conversación transitan aladas - según la antigua fórmula epea pteroenta - entre un personaje y otro, entre poeta y musa, entre poema y auditorio.

Fórmula y variación - epea pteroenta - propone una organización rutinaria, repetida, orgánica y previsible, derivada en la repetición ritual. Foley (1995) y Nagy (1996, a-b) han argumentado extensamente acerca de estas dos posibilidades interpretativas, insistiendo cada uno en la idea de iteración como marco 
regulatorio de la poesía épica en su composición y en su ejecución. La parataxis épica analizada desde la perspectiva crítica señalada es repetición variada y cadenciosa a través de todos los alomorfos de una estructura y de una palabra, una composición aditiva, sumatoria que se vierte jerárquica en el lenguaje. De tal manera, una visión estética comunica por sí misma la comprensión del acontecimiento narrado y sus vinculaciones contextuales.

En los poemas homéricos el poder se deposita en objetos: el arco, el cetro, que exponen la simbolización física; el poder, incluso se apoya y depende de un nítido dominio en el lenguaje: gritos de guerra, discursos superpuestos, diálogos frustrados, súplicas efectivas articulan códigos de funcionamiento social y establecen la perspectiva temporal necesaria.

Entre las epea pteroenta, entre "aladas palabras", arco y cetro, palabras y objetos, se hallan como alomorfos de una repetición significante, marcan en el ámbito de los poemas homéricos unos hitos del poder, narran - como otros objetos épicos - por sí mismos una breve historia, resultan palabra narrada y explicada y, como atributos del poder, dirimen el protagonismo y los desenlaces tanto en Ilíada como en Odisea.

Constituye nuestra hipótesis que, en el ámbito de Ilíada, aqueos y troyanos presentan un lenguaje diferente y que los debates sobre el poder se presentan de modo recurrente en el campo aqueo, en la coalición menos institucionalizada y con menos sede comunitaria. Esta coalición "panhelénica" convierte el campo de batalla en campo verbal y que, en ese ámbito, arco y cetro prevalecen como imágenes de los problemas del lenguaje y el poder. En el ámbito de Odisea, arco y cetro representan el linaje de los Laertíadas, lo aseguran y perpetúan. En ambos poemas, además de advertir las peculiaridades del lenguaje el discurso épico celebratorio se ve discutido por la presencia de personajes originarios una tipología de relatos que constituyen o conforman los "alomorfos" del relato épico. Tersites e Iro proporcionan una contrabalanceada organización discursiva, una intromisión de un discurso opositor al dominante epos. ${ }^{1}$

1 Sobre la intromisión de Tersites como un personaje del yambo a causa de su aspecto físico, que no sigue el paradigma de belleza heroica, y a causa de su uso del lenguaje como una inserción del iambos en Ilíada son interesantes los comentarios de Suter (1993, p. 1-50). En cuanto a la escena de Iro en Odisea 18.1-158 De Jong opina que es una de las escenas" burlescas" de Odisea, comparable al canto sobre los amores de Ares y Afrodita en 8.266-366. Acaso la mayor relevancia de estos contenidos reside en que son presentados como espectáculo risible, para sendos espectadores - guerreros, dioses, 
Los proemios épicos suministran la primera vía de acceso a la propuesta de interpretación, y para el caso, el proemio de Ilíada irrumpe con el campo temático de la menis, que aceptamos benévolamente. La cólera de Aquiles no posee una única lectura. Menis, como tantos otros sustantivos de raíz verbal con sufijación -is, sustantivo que indica proceso y acción, propone un campo temático "performativo" de "puesta en acto". Redfield $\left(1978^{2}\right)$ sostiene que la cólera, como acción, manifiesta un paradigma ético y en su análisis desde la perspectiva de la Ética Nicomaquea, la cólera de Aquiles constituye un "error trágico", es decir una acción con consecuencias nefastas, una acción que expone la existencia heroica en la crítica intersección entre naturaleza y cultura. Formulada en lenguaje poético y no en el lenguaje de la reflexión filosófica, la menis de Aquiles constituye fundamentalmente una visión estética y es dentro de esa visión estética que resulta una cuestión de poder, una cuestión de pasión y una cuestión de lenguaje.

Situación crítica para un contingente de guerra, la menis de Aquiles se diseña como un duelo entre líderes y el séptimo hexámetro del proemio opone en los extremos del verso Atrida / Aquiles:



El antagonismo descripto en la estructura física del verso ubica en el inicio y fin del verso la expresión del conflicto. En esta estructura, Kahane (1994, 5-16) ha señalado estadísticamente que los finales de hexámetros contienen la denominación propia de los personajes protagónicos mientras los inicios de verso contienen conceptos en acusativo, menin, andra que definen contenidos temáticos. En la tensión entre el objeto acusativo que inicia el proemio y el sujeto nominativo que suele conformar el último pie de los hexámetros, el proemio de Ilíada hace de la cólera una oposición agónica, un debate del poder de Agamenón promovido por Aquiles, y la parte central del hexámetro limita con los epítetos el conflicto entre un $\alpha$ $v \alpha \xi$ ¿ $\alpha \delta \rho \omega \hat{\omega} \nu$ y un $\delta \hat{i} o \zeta$, entre un soberano de hombres y un ser de potencia "divina". Los epítetos, tan depreciados por su valor formulario, devienen deícticos de la función social y jerárquica de cada personaje.

pretendientes - y que, en dichas escenas, se presenta una implantación de modalidades discursivas, es decir sobre el diálogo bélico se implanta una escena de pugilato, o una escena de engaño divino resulta impuesta sobre un discurso de aedo. Cfr. De Jong (2001, p. 438-439). 
Al observar los usos de la palabra skeptron, especialmente, en el canto I de Ilíada resulta evidente que la cólera de Aquiles es una cuestión de debate del poder. Del cetro de Crises penden las ínfulas de Apolo, del arco de Apolo surgen los dardos mortales, sobre su cetro juramenta Aquiles que Agamenón lamentará despreciarlo. La desestabilización del poder de Agamenón se completa con el uso de comparativos, como basileuteros, que dan cuenta cabal de un poder des-localizado: Agamenón es rey mayor, pero la configuración del poder en Ilíada se traslada a un espacio liminar y marginal: la tienda de Aquiles.

El índice de ocurrencia del debate en torno al cetro y al poder comparativo entre basileis continúa en el canto IX, cuando ya no se hace necesaria una construcción del hexámetro que revele tan exhaustivamente el enfrentamiento directo Atrida/Aquiles propuesto en el proemio.

Ilíada presenta una guerra panhelénica en que los conflictos internos son más graves que los riesgos ante el enemigo, como correlato de otros aciertos compositivos ya reconocidos en Poética (1456 $\underline{a}, 1459$ b y ss.), el poema no sólo restringe su temporalidad al último año de la guerra, sino que omite toda la conformación previa de la coalición. Desde el punto de vista narrativo, la remoción de Aquiles por su menis, coloca una figura de reemplazo: Diomedes.

Por una parte, en el canto IX de Ilíada, Diomedes ejerce ese papel sustituto en el ágora y el factor determinante de su intervención proviene del concepto de alké, energía bélica, que garantiza la supervivencia en el combate y que se vierte lingüísticamente. Diomedes puede prevalecer porque su voz, según informa el epíteto, es potente para prevalecer en el campo de batalla; se impone, además, sobre el signo externo del poder que representa el cetro.

Arco y cetro relativos a Apolo cobran importancia mientras permanece vigente una transgresión de las áreas sagradas, el cetro del basileus y el que concede la palabra en el ágora, en el duelo Aquiles / Agamenón, es un cetro que, perdido el mecanismo vital - ya no dará hojas ni ramos ni reverdecerá - está estabilizado como signo del poder de los aqueos que imparten justicia y guardan las leyes de Zeus:

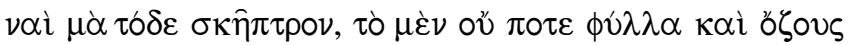

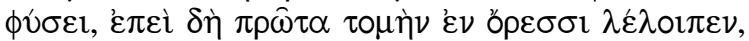

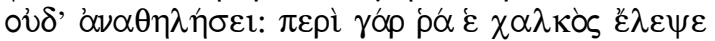

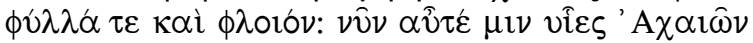
'¿v $\pi \alpha \lambda \alpha$ un

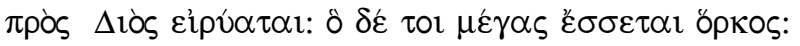


Sí, por este cetro que ya no producirá hojas, ni ramos porque dejó el tronco en la montaña; ni reverdecerá, porque el bronce lo despojó de las hojas y la corteza, y ahora lo empuñan los aqueos que administran justicia y guardan las leyes de Zeus. Este será para ti un gran juramento.

El juramento de Aquiles citado (Il. I.234-238) deja asentada la versión del cetro de la justicia en manos colectivas, las de los aqueos, no en las manos individuales de Agamenón, el cetro que fue organismo vivo, queda fijo y firme, invariable, en las themistas proporcionadas por Zeus. La tensión individuo/comunidad atraviesa el primer canto de Ilíada fundando la serie de reflexiones sobre el riesgo heroico y la timé correspondiente.

En el nivel del discurso y en el nivel del relato, el ataque al poder del basileus Agamenón provoca la aparición de una figura marginal cuya descripción constituye el opuesto de las excelencias heroicas. El episodio de Tersites en el canto II, añade en principio un elemento de tensión similar a la querella del primer canto, aunque la presentación del personaje resulta dramática: él es una suerte de "máscara", un glotón de lenguaje desarticulado en II.212.-214, odiado por Aquiles y Odiseo. Su performance discursiva lo convierte en figura yámbica y el episodio termina diluyendo al tensión en un apaleo cuasi - cómico, por supuesto con la mediación de un cetro. El lenguaje de Tersites no resulta efectivo en la discusión del cetro de Agamenón porque el personaje no guarda proporción entre palabras y hechos, el adjetivo con el que lo califica Odiseo akritomuthe en el verso 245, manifiesta su falta de moderación. Figura excesiva e inarmónica, Tersites no logra ningún fin práctico con su discurso rebelde. Representa la competencia entablada contra el discurso épico por un género discursivo menor: la intromisión de un modo poético de burla y reproche frente al modo discursivo estrictamente épico: el encomio. ${ }^{2}$

Por otra parte, el canto IX proporciona con más claridad la segunda línea interpretativa de la menis, es decir la cólera como cuestión afectiva. Una vertiente etimológica parece sostener la idea de menis como vocablo conectado al enojo de la pasión afectiva. Ilíada propone la idea de intercambio equivalente de un geras por otro, Criseida por Briseida. En su calidad de geras cada una de estas figuras femeninas representaría una versión oral variada sobre el mismo tema (Dué, 2002, p. 21-36), y demostrarían el modo compositivo original de Ilíada: una contienda

2 Cfr. Nagy (1996ª , passim) y su comentario sobe los orígenes de epos. 
por una mujer. El mismo valor de intercambio sostiene el valor punitivo y sublimado del rescate por un crimen, el valor sublimado que reemplaza la retribución violenta por poiné. Sin embargo, estas nociones de intercambio equivalente, se hallan fuertemente discutidas por Aquiles. En el canto IX Aquiles formula argumentaciones imprevisibles en la respuesta que ensaya ante Odiseo, el ataque a Troya recibe interpretación en el lenguaje del héroe y es evidente que Aquiles parece adherir a un funcionamiento social más arcaico, en el que no se admiten intercambios. Si la palabra menis corresponde efectivamente a una raíz vinculada con la pasión erótica, entonces el gran contenido temático de Ilíada, la cólera de Aquiles, proviene del afecto a su alochon, y su formulación se sintetiza en los siguientes versos del canto IX.337-343:

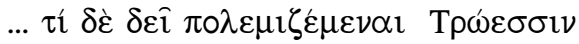

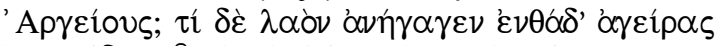

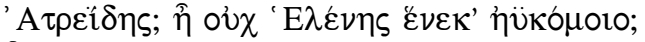
$\hat{\eta} \mu$ ovv 'A

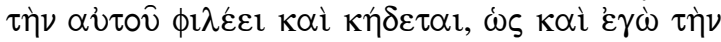



¿por qué los argivos han tenido que mover guerra tan grande a los teucros? ipor qué el Atrida ha juntado y traído el ejército? ¿No es por Helena, la de hermosa cabellera? Pues, ison los Atridas los únicos hombres, de voz articulada, que aman a sus esposas? Todo hombre bueno y sensato quiere y cuida a la suya, y yo apreciaba cordialmente a la mía, aunque la había conquistado con la lanza.

Cuestión de cetro y privilegios, la disputa entre Aquiles y Agamenón, adquiere un perfil más humano y limitado. En la guerra impersonal y desafectada que combate Aquiles, el conflicto de liderazgo le impone motivos pasionales y subjetivos de contienda: primero Briseida; más adelante, Patroclo.

Otras dos cuestiones relativas al arco y el cetro como signos de los problemas de la palabra y el poder resultan dignas de mención en los poemas homéricos. La primera cuestión está relacionada con una famosa omisión en el discurso del embajador Odiseo como mensajero de Agamenón. Se trata de la estratégica omisión que Odiseo realiza de los imperativos que Agamenón pronuncia, en IX.158-161: 




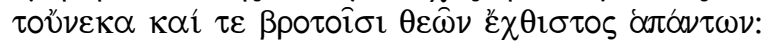

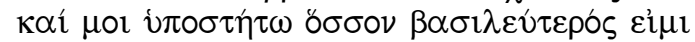



Que se deje domar, pues por ser implacable e indómito Hades es, para los mortales, el más aborrecible de todos los dioses y que se me someta, ya que me enorgullezco de superarlo en poder y en nacimiento.

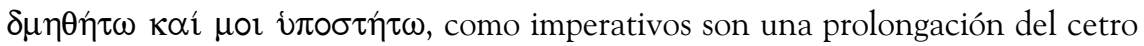
de Agamenón, por esta razón, Odiseo los omite. El primer imperativo se refiere al poder de Agamenón como una relación de sujeción animal, someterse al yugo, por la vía de la autoridad o por la vía del matrimonio. El segundo imperativo, de espacialidad más explícita impone el sitio de Aquiles debajo del sitio de Agamenón. La repetición de Odiseo resulta intencionadamente elíptica.

La tercera vía interpretativa, es ver la menis como una problemática del lenguaje y, específicamente, del lenguaje poético. La menis es contenido épico circunstancial ya que el mayor contenido temático de la épica, determinado por su género discursivo se define por klea; pero icuál es la hazaña de Aquiles? ¿Acaso su inconmensurable enojo? Este mismo sólo abastecería la comprensión de la primera parte de Ilíada hasta el canto XVI; o acaso se trata la potencia bélica desplegada por motivos afectivos, que lo convierte en el mundo reglado del símil en fuerza elemental, combatiente del río y, potencialmente, fiera salvaje de voracidad caníbal en los cantos finales, especialmente desde el canto XX hasta el canto XXII.

La confrontación mítica entre aqueos y troyanos compone en la ficción una versión comparativa de dos sociedades que se diferencian por el uso del lenguaje. Del lado aqueo, son recurrentes las reuniones colectivas y el lenguaje tiene por finalidad el reproche o la censura pública, las circunstancias presentadas son fuertemente convencionales: un ágora, un consejo de los jefes, una embajada. En el sector troyano, prevalecen los usos no públicos del lenguaje. Salvo el lamento funeral, los discursos son íntimos, domésticos, no dirimen la funcionalidad de los héroes como figuras públicas y, en todo caso, esta cuestión queda relegada al monólogo de su adalid en el canto XXII.99 y ss. y al sentimiento personal de responsabilidad cívica que el personaje acusa. La antítesis resulta evidente, la ciudad da sede al pueblo que no expone un uso público del lenguaje. Del lado troyano abundan los relatos de cautiverio femenino, Andrómana ensaya el suyo en el canto VI y la seudo-cautiva Helena advierte que su relato corresponderá al tejido de 
un canto. Entre las huestes aqueas, Briseida evoca la memoria de su cautiverio en el canto XVIII y la lira que ejecuta Aquiles en el canto IX testimonia otro episodio de rapiña bélica.

El léxico puntualiza el valor colectivo del lenguaje. En el campo aqueo, son recurrentes las expresiones de pudor que afeminan a los héroes vistos como mujeres cobardes (en V.787 y en VIII.228, por ejemplo, “aqueas más que aqueos”, son invocados por Hera y por Tersites) o asegura una situación competitiva en que los insultos constituyen el camino a la obtención del título de " mejor entre los aqueos" por el desplazamiento de otro.

Entre las formas fuertemente convencionales de uso del lenguaje, el texto de Ilíada coloca en abismo la versión mítica de Meleagro IX.434-565, un héroe susceptible a la historia de cautiverio que la esposa Cleopatra utiliza como estrategia persuasiva, a los efectos de animarlo a combatir. La polarización entre Agamenón y Aquiles se disuelve a través de una cuestión de lenguaje y una cuestión afectiva: la súplica de Patroclo y la pérdida subjetiva dan otro contenido al objeto de la menis inicial. Si al principio del poema el hexámetro oponía Atrida /Aquiles y varios cetros en un juego de poder y en una discusión de liderazgo, en el canto XVI y subsiguientes las palabras de Patroclo - una versión funcional a la de Cleopatra en el mito de Meleagro - promueven el desplazamiento de la menis.

Cuestión de palabras, no es el tropo alegórico de las Litai en IX.502-514 el que persuade a Aquiles, ni siquiera el relato mítico en sí. Así como a Meleagro lo persuadió la narración femenina del cautiverio, a Aquiles sólo lo persuadirán las palabras y el gesto afectivo de Patroclo, en el símil de los versos iniciales del canto XVI, "una niña pequeña que abraza a su madre".

El lenguaje de Aquiles en el canto IX merece una consideración especial. Su querella contra Agamenón, lo distancia de la comunidad, declara fehacientemente no tener motivos íntimos para guerrear contra los troyanos, se coloca como un marginal migrante deshonrado, un $\alpha \tau i ́ \mu \eta \tau o \nu ~ \mu \varepsilon \tau \alpha \nu \alpha ́ \alpha \tau \eta \nu$ (IX.648 y XVI.58-59). En este sentido su visión es única entre los aqueos, y también es único el lenguaje que utiliza para expresar esta experiencia, más asimilable al lenguaje hesiódico en Erga, por la utilización de vocablos como aergos en IX.320, un término aplicado reiteradamente por Hesíodo al agricultor. En Erga, Hesíodo se percibe ficcionalmente a sí mismo como un desheredado, una focalización de ficción que no dista en absoluto del modo en que Aquiles percibe su propia situación. Como focalizador narrativo Aquiles se desplaza desde el sitio de "mejor de los aqueos" al de un desheredado que carece de padre, propiedad y prestigio social. 
Despojado de los atributos de la vida comunitaria, se equipara con los personajes más bajos y degradados, los insultos que dirige a Agamenón son del mismo rango que los proferidos en clave yámbica por Tersites.

Aquiles propone una visión de Agamenón como un basileus excesivo y codicioso como alguno de los reyes que presenta Hesíodo, reyes devoradores de dones, basileas dorofagous (Erga 38-39 y 263-264). Aquiles condena a Agamenón como demoboros, I.231, devorador de su pueblo. El lenguaje de Aquiles parece mas bien hesiódico, y no sólo por el pesimismo desencantado que expresa ante el decadente soberano que se le impone, sino porque este tipo de lenguaje es el que utiliza para cuestionar la validez de la ideología de la épica heroica.

En lo que atañe a la menis como cuestión de poder, el canto XXIV clausura el duelo Aquiles/Héctor con el duelo conjunto ya no combativo Aquiles/Príamo. El cetro de Príamo que ha servido para habilitar la salida del anciano basileus desde la ciudad, desaparece ante Aquiles. La estructura del hexámetro diluye el protagonismo, ni el nombre de Aquiles ni el de Príamo ocupan los extremos de los versos, ubicados los nombres en el centro del verso, el lenguaje poético muestra la dilución de la cólera y de las oposiciones. Por otra parte, es en el discurso paterno de Príamo en el que Aquiles es desplazado al centro del verso y es en el discurso paterno del tutor Fénix que el mito reviste carácter de Exempla.

Aunque Odiseo, Fénix, el mismo Agamenón - que aspira a prohijarlo con una boda - y Príamo utilizan frente a Aquiles el léxico de la orfandad, en que la memoria del padre debe reconstruir los vínculos con la comunidad; el lenguaje de Aquiles hacia el final del poema se vuelve fuertemente paradigmático: el mito de los dos toneles en XXIV.527-533 y el mito de Níobe en XXIV.620 son muestra cabal de la propensión educativa más madurada que manifiesta el personaje al final.

La menis, cuestión de poder, cuestión afectiva, cuestión de lenguaje es la expresión del poder del lenguaje poético, el narrador presenta las causas y la erupción fragorosa de una menis que se decide en analepsis, prolepsis, elipsis y encantamiento del auditorio. Como el guerrero impone su voz en combate, el narrador impone la composición y a él se le impone la voz de la musa y su visión compone una muralla destruida por anticipado en el lenguaje canto XII antes de que finalice la guerra, o compone el discurso de los héroes agonizantes que vuelven las klea, las hazañas ajenas una cosa efímera, una palabra alada, un euchos, una cosa fugaz concedida en tercer término y devaluada por la intervención de un dios. 
La repetición y la adición de secuencias constituye la base de la composición épica. Es esta una afirmación consuetudinaria que ha sido objeto de distintas valoraciones, y que se ha aplicado a dos fragmentos discutidos, la repetición que implica el catálogo enumerativo de naves y líderes y a los parentescos expandidos en los patronímicos del epíteto. La relación entre el catálogo y las cuestiones del poder involucradas por el cetro vuelven las referencias la líder, al territorio y al número de naves una cuestión estricta de poder. Si bien literariamente el catálogo del canto II de Ilíada, propone un lenguaje poético enumerativo que bien puede postularse como un modo compositivo incipiente de la narración, resulta a la vez una versión performativa, una puesta en acto del arribo inicial de la coalición, vale por una analepsis y propone una construcción actual. Otra adición la constituyen los patronímicos y los parentescos que corroboran los alcances del cetro. Territorio y poder van de la mano, héroe y témenos son coexistentes, ${ }^{3}$ como lo manifiesta Heródoto. $^{4}$

El parentesco mítico constituye el tercer mecanismo de poder y es prolongación del cetro en los descendientes y en la hospitalidad que radica valores cooperativos expandiendo el poder por gratitud. Tucídides se apropiará de este argumento y lo colocará en boca de Pericles en la Oración Fúnebre. ${ }^{5}$ Cfr. Tucídides,

La inauguración de Ilíada compromete un designio de Zeus con ofensas previas a Apolo y el arco de Apolo atraviesa varios cantos proveyendo la iluminación

3 Seguimos la definición de Liddell \& Scott (1968, p. 1774), que distingue dos acepciones básicas del vocablo. En el contexto épico es el territorio marcado como posesión oficial. La evolución del campo semántico derivó en su aplicación ritual. Ya que con posterioridad designó el terreno consagrado a un dios o a un héroe. Creemos que es plausible ver en el discurso de Sarpedón una expresión previa de este sentido ritual.

${ }^{4}$ Sabemos por Heródoto (2.162-163) que los guerreros egipcios también disfrutaban de

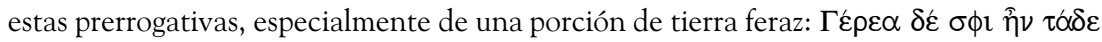

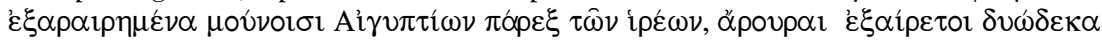

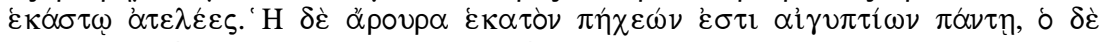

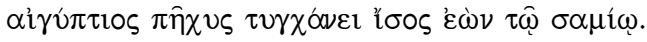

5 Cfr. Tucídides, Historia, II.40.4.1 a 5.3. El argumento se basa en la expansión de la

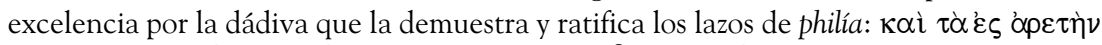

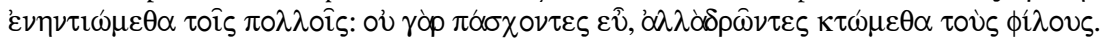

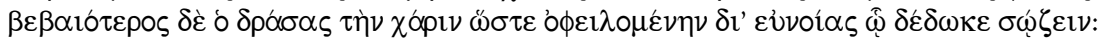

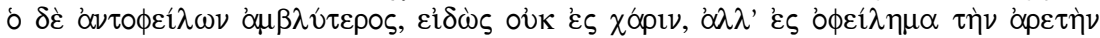

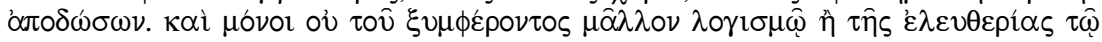




de la condición humana en los héroes que están a punto de morir. Licaón, Sarpedón, Patroclo atestiguan la iluminación fatal de la cercanía de Apolo.

Si algunos cantos de Ilíada admiten la calificación de délficos por la coercitiva dilucidación de la condición humana que el dios Apolo impone, un ejercicio de gnothi seauton muy evidente, por ejemplo, en la Patroclía ,no menos influenciados por Apolo se hallan los pasajes decisivos de Odisea.

El arco y el cetro proponen en Odisea el desenlace apropiado para los conflictos internos. La restauración del basileus se concreta en la noche ritual de Apolo y con el instrumento de Apolo, el arco que narra un relato de hospitalidad. El arco de Ifito es un presente de hospitalidad que desarrolla la historia de la estirpe de Eurito, fue objeto de un itinerario de padre a hijo, de huésped a anfitrión, de Odiseo a Telémaco y en el canto 21 es instalado como herramienta de la competencia final para la conquista de Penélope. El certamen que modela los certámenes posteriores y que recibe la categorización de athlos y de principio de la matanza?:





... proponer a los pretendientes el gris hierro en la sala de Odiseo, instrumento de la competencia y comienzo del crimen.

En el lenguaje de Odisea, el arco es instrumento de canto, suena y resuena en las manos de Odiseo y el símil lo instala en el ámbito del lenguaje poético para incrementar su poder


'p

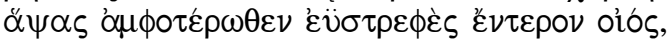

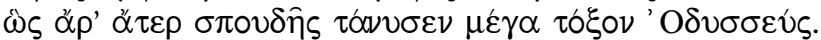

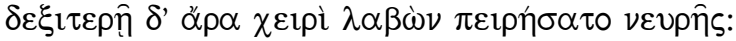
ฑं $\delta$ '

Como un hábil citarista y cantor tiende fácilmente con la clavija la cuerda formada por el retorcido intestino de una oveja que antes ató a un lado y a otro, así, de modo previsible, sin esfuerzo alguno, Odiseo armó el arco. Ensayó la cuerda con la diestra y ella cantó bellamente semejante en su voz a una golodrina. (Od. 21.406-411) 
La asimilación entre arco e instrumento musical, continúa y asegura la presencia de Apolo como el dios que ilumina los instantes de la muerte. El símil transfiere el poder del arco al mundo del canto y reitera el poder de Odiseo como un aedo, ya ponderado en el mundo de los apólogos porque sus palabras tenían forma como las palabras poéticas cantadas. La competencia entre Odiseo y los pretendientes resulta una violencia sublimada en un canto: la matanza es un relato producido por el arco-cítara y el ejecutante meramente produce el sonido del canto de un ave.

En el canto 22 de Odisea la matanza de los pretendientes propone un marco de palabras y ritos de clarificación para la restauración del cetro de Odiseo. El acabado cumplimiento del certamen se ofrece en el valor resultativo del perfecto ektetelesai 22.5, Odiseo alterna el blanco de las hachas por otro blanco, skopon allon, que le proporcionará un euchos concedido por Apolo. Es preciso hacer hincapié en este vocablo en el discurso de Odiseo. El certamen tiene la organización convencional del duelo bélico, es el pasaje de Odisea más asimilable a una batalla en Ilíada, se reúnen agonísticamente pares de discursos y personajes, uno de los cuales morirá. Odiseo repite esta situación y espera como Sarpedón en Ilíada XII.328, un euchos, un lenguaje de tenor suplicante que memore su hazaña. Espera que su poder se extienda en el lenguaje.

Sobre la actuación de Odiseo como una restauración ritual del orden de la casa, son explícitas las palabras del aedo que transfiere la matanza al orden de las divinidades, y convierte el canto 22 en una teodicea. El aedo impone un lenguaje de autodidacta y se considera capaz de entonar todo tipo de canto ante él como ante un dios.

Si superamos la anecdótica comparación entre héroe y divinidad, los cantos que propone entonar Femio, reintegran en el lenguaje del poema la cuestión de poder iluminador, fulminador de Apolo, y también del poder aniquilador de Odiseo, arco en mano en la festividad apolínea. Odiseo ejecuta a los pretendientes como un eximio arquero, obtiene un athlon relativo a la recuperación de las estructuras de comunicación, aedo y heraldo son disculpados. Sin embargo, Odiseo acomete muertes masculinas como un atleta, en tanto que las muertes femeninas son ejecutadas por Telémaco como un eximio marinero. El cetro reaparece en la distribución de los castigos, al basileus restaurado corresponde el dominio del poder masculino, a su vástago una resolución doméstica.

El canto 24 de Odisea dirime la cuestión del poder de Odiseo en el campo fónico del lenguaje poético y en el campo del símil. El poder de Odiseo se prolonga en el grito bélico que aterra a los deudos de los pretendientes, y en su voracidad de águila que persigue a una presa. 
En Odisea, el lenguaje poético tiene el poder de ordenar y desordenar en una estructura compleja los entresijos de la narración de viaje, y el lenguaje de la diosa Atenea refrena un belicismo inútil, porque ya no produce kleos.

También Odisea proporciona una muestra de la competencia entre el modo poético del encomio y el modo poético del reproche y es través de la intromisión de al figura de Iro y su combate por la comida y a partir de la figura de Odiseo mendigo (cantos 18 y 19). El cuestionamiento al poder celebratorio del lenguaje épico culmina en la visión del héroe que para asegurar su liderazgo elige hablar como un antihéroe, como un mendigo,

En ambos poemas el arco y el cetro son componentes de la ideología heroica, y en ambos poemas al mismo tiempo se instala la problemática entre un modo poético y otro, en la conceptualización de Nagy, los valores competitivos representados por el arco y el cetro son discutidos en el ámbito de una competencia de lenguajes poéticos, en que las epea pteroenta dirimen si prevalece la poetry of blame o una poetry of praise (Nagy, $1991^{3}$, cap. 2).

Este antagonismo tradicional resulta programático en los poemas homéricos para proponer en "aladas palabras" los modos de representar en la composición poética oposiciones culturales tan fuertes como la configuración de la matriz heroica con su lenguaje y sus opuestos correspondientes.

\section{REFERÊNCIAS BiBLIOGRÁFICAS}

\section{Ediciones:}

Allen, T. W. Odyssey. Oxford: 1917.

LEAF, W. The Iliad. Amsterdam: 1960.

Leaf, W.; Bayfield, M. A. The Iliad of Homer. New York: 1960.

Heubeck, A.; Hoekstra, A. A Commentary on Homer's Odyssey. Oxford: 1990. v. II.

Heubeck, A.; West, S.; Hainsworth, J. B. A Commentary on Homer's Odyssey. Oxford: 1991. v. I.

Heubeck, A.; Fernández-Galiano, M.; Russo, J. A Commentary on Homer's Odyssey. Oxford: 1992. v. III. 


\section{Estudios modernos:}

BAKker, E. J. Poetry in Speech. Orality and Homeric Discourse. Ithaca: 1996.

Ballabriga, A. Les fictions d'Homère. L' invention mythologique et cosmographique dans l' Odyssée. París: 1998.

Bolmarcich, S. "OMOFROSUNH in the Odyssey". Classical Philology. v. 96, n. 3, p. 205-213, 2001.

Cook, E. The Odyssey in Athens. Myth of Cultural Origins. Ithaca and London: 1995.

Crotty, K. The Poetics of Supplication. Ithaca: 1994.

De Jong, I. J. F. Narrators and Focalizers. The Presentation of the story in the Iliad. Amsterdam: 1987.

. A Narratological Commentary on the Odyssey. Cambridge: 2001.

DOugherty, C. The Raft of Odysseus. Oxford: 2001.

DuÉ, C. Homeric Variations on a Lament by Briseis. New York: 2002.

Foley, J. M. The Singer of Tales in Performance. Bloomington: 1995.

Ford, A. Homer. The Poetry of the Past. New York: 1992.

GiLl, C. Personality in Greek Epic, Tragedy and Philosophy. Oxford: 1996.

GonzÁlez de TobIa, A. M. "Un soliloquio escénico significativo. Ilíada, XXII,99.

130". Praesentia, Revista Venezolana de Estudios Clásicos. Año1, n. 2-3, p.109126, 1998.

KaHANE, A. The Interpretation of Order. Oxford: 1994.

Lateiner, D. Sardonic Smile. Michigan: 1995.

Lynn George, M. Epos: Word, narrative and the Iliad. Hong Kong: 1988.

Nagy, G. The Best of Achaeans. Baltimore and London: 199133. . Poetry as performance: Homer and beyond. Cambridge: 1996a. . Homeric Questions. Texas: 1996b.

Peradotto, J. Man in the Middle Voice. Princeton: 1990.

ReDFIeld, J. Nature and Culture in the Iliad. Chicago: $1978^{2}$.

SiLK, M. "The Odyssey and its explorations" en Fowler, R. The Cambridge Companion to Homer. Cambridge: 2004. p.31-44.

Stanford, W. B. The Ulysses Theme. Oxford: $1968^{2}$.

Taplin, O. Homeric Soundings. Oxford: 1992. 
Vernant, P. Mythe et pensée chez les Grecs. París : 1965.

Vidal Naquet, P. "Land and Sacrifice in the Odyssey. A study of religious and mythical meanings". In: ScheIn, S. L. (ed.). Reading the Odyssey. Selected Interpretative Essays. Princeton: 1996. p. 33-55.

Vivante, P. Homer, New York: 1985.

Zecchin de Fasano, G. C. "Cuatro discursos de Odiseo en el canto II de Ilíada". Actas del XIII , Simposio Nacional de Estudios Clásicos. La Plata, p. 233-239, 1997.

. Odisea: Discurso y Narrativa. La Plata: 2004.

\section{Informe}

Una versión preliminar de este artículo fue presentada como conferencia en la Universidad de Morón el 16 de setiembre de 2006.

ZECCHIN DE FASANO, Graciela. The bow and the sceptre: problems concerning word and power in Homeric poetry.

ABSTRACT: The present article analyses the semantic value contained in the epic formulae epea pteroenta and his variations as expression of the antagonisms proper of epic narrative. Its also analyses the way in which these antagonisms - among heroes, narrative modalities, modes of design of the plot and conceptions of power - are featured in two objects through repetitive use and symbolic value: the Bow and the Sceptre.

KEYWORDS: Homer; Iliad; Odyssey; word; power. 